International Journal of Advanced Trends in Computer Science and Engineering

Available Online at http://www.warse.org/IJATCSE/static/pdf/file/ijatcse4091.42020.pdf

https://doi.org/10.30534/ijatcse/2020/4091.42020

\title{
Enhanced DTC induction motor drives- THD reduction multilevel inverter fed drives control
}

\author{
S. K. Chien ${ }^{1}$, S. Y. Sim ${ }^{1 *}$, W. M. Utomo ${ }^{2}$, F. B. Mustafa ${ }^{1}$, N. B. Sahari ${ }^{1}$, F. H. B. M. Noh ${ }^{1}$, N. A. B. Zambai ${ }^{1}$, \\ H. L. Kah", A. J. M. S. Lim $^{3}$, G. Y. Sim $^{2}$ \\ ${ }^{1}$ Department of Electrical Engineering Technology, Faculty of Engineering Technology, Universiti Tun Hussein \\ Onn Malaysia Kampus Pagoh, Hab Pendidikan Tinggi Pagoh, KM 1, Jalan Panchor, 84600 Panchor, Johor \\ ${ }^{2}$ Department of Electrical Engineering, Faculty of Electrical and Electronic Engineering, Universiti Tun Hussein \\ Onn Malaysia, 86400 Parit Raja, Batu Pahat, Johor, Malaysia \\ ${ }^{3}$ Departmrnt of Infrastructure and Geometic Engineering, Faculty of Civil and Environmental Engineering, \\ Universiti Tun Hussein Onn Malaysia, 86400 Parit Raja, Batu Pahat, Johor, Malaysia \\ ${ }^{4}$ Departmrnt of Electrical and Computer Engineering, Faculty of Engineering and Science, Curtin University \\ *Corresponding author E-mail: sysim@uthm.edu.my
}

\begin{abstract}
Direct Torque Control (DTC) is a control method that controls speed and torque of Induction Motor (IM) directly, accurately and independently without pulse encoder feedback from the motor shaft. However, in Fast Fourier Transform (FFT) analysis of Total Harmonic Distortion (THD) for motor drive, DTC control with a conventional inverter leads to higher THD. Therefore, the main challenge of this study is to reduce the THD in three-phase line current DTC IM drive while maintaining the drive's speed and torque performance. A Multilevel Inverter (MLI) based DTC IM drive system is proposed in this study with the aim to reduce THD in three-phase line current while remaining the good speed and torque response of DTC IM drive system. The proposed MLI are realized by three-level neutral point clamped (NPC) MLI fed DTC of IM. In proposed MLI, pulse width modulation (PWM) is a control strategy used to control the switching at appropriate conducting angles. Proposed MLI based THD reduction DTC IM drive has several advantages over conventional inverter, which enable the operation with multiple switches instead of one switch that generates higher output voltage with low distortion, has ability to operate under low switching frequency, and it allowed the system to work with renewable energy to convert $\mathrm{DC}$ voltage into $\mathrm{AC}$ voltage. In order to verify the effectiveness of proposed MLI in THD reduction in DTC IM drive, simulation is conducted with MATLAB Simulink to investigate the performance and THD of IM drive system under different operating speed. The results show the THD of the three-phase line current has been decreased with the implementation of proposed MLI based THD reduction DTC IM drive as compared with the conventional DTC IM drive.
\end{abstract}

Key words : Direct torque control; Total harmonic distortion; Multilevel inverter; Induction motor; Fast fourier transform.

\section{INTRODUCTION}

Induction motor (IM) is an alternating current (AC) motor that has been widely used in industry as variable speed drives to replace DC motor due to several advantages over direct current (DC) motor includes greater efficiency, simple and robust construction, cheaper in price, and absence of brushes that require less maintenance [1][2]. IM has dynamic and nonlinear characteristics which require advanced control techniques including field-oriented control (FOC) and direct torque control (DTC) for high performance variable speed drive applications [3]. Both of the advanced control techniques have similarities in providing better torque response in transient and steady-state conditions with direct control of torque and flux separately [4]. However, DTC has gained more attention in research over FOC due to several advantages of DTC such as structure with ease control, fast torque response, robustness against the change of rotor parameters, reduce the computational cost, and less dependency on motor parameter [5]-[10].

Multilevel Inverter (MLI) is an inverter that used series of semiconductors for generating higher output voltage with better harmonic spectrum and achieves higher voltage with the stepped waveform in the maximum available device rating which has recently increased interest in both research studies and industry applications [11][12]. Due to the high efficiency, low electromagnetic interference (EMI), and low switching losses, MLI is suitable in motor drive applications with high power rating [13][14]. MLI is categorized into three different types, which are neutral point clamped (NPC), flying capacitors (FC), and lastly, cascaded H-bridge inverter (CHB) [15][16]. By compare MLI with the conventional two-level inverter, MLI with high switching frequency PWM has several advantages over conventional two-level inverter. MLI operates with multiple switches instead of one switch, it generates higher output voltage with low distortion, has 
S. K. Chien et al., International Journal of Advanced Trends in Computer Science and Engineering, 9(1.4), 2020, $269-276$

ability to operate under low switching frequency, and MLI can worked with renewable energy to convert DC voltage into AC voltage [15][17]. The topology of MLI is shown in Figure 1 , which divided into two types namely common DC sources (NPC and FC) and separated DC sources (CHB). NPC MLI is mainly composed of two conventional two-level voltage source inverter (VSI) that connected together with one over other with some modification. This NPC MLI is widely accepted in the industry due to its high voltage capability with maximum efficiency in optimum operation. FC MLI required lots of capacitors in this topology which bring about capacitor balancing problem. In this FC MLI, the load is either connected to anode or cathode bar through flying capacitor with opposite polarity to obtain zero level voltage. CHB MLI are formed from two or more single-phase H-bridge inverters with back to back series connection. Three different voltage level, $+V_{d c}, 0$, and $-V_{d c}$ can be generated with a single H-bridge inverter. The CHB MLI is able to produce output with $2 \mathrm{~N}+1$ levels with the series connection of $\mathrm{N}$ single H-bridge [18][17].

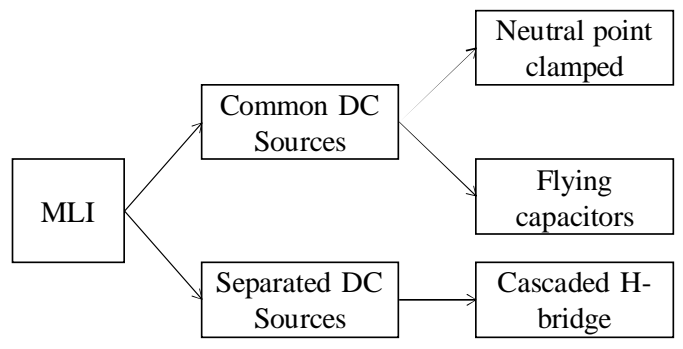

Figure 1: Topologies of MLI

A three-phase DTC IM drive with and without MLI is presented in this paper to minimize the THD of the motor drive at different operating speeds. MATLAB Simulink is used to stimulate and study THD of DTC IM drive with conventional inverter and three-level MLI at low (300 rpm), medium $(850 \mathrm{rpm})$ and high speed $(1400 \mathrm{rpm})$. The results are compared between conventional inverter with the proposed three-level MLI under the same conditions. This paper has been divided into four sections. In section II, the mathematical model of IM is discussed. Section III explains the proposed MLI based THD reduction DTC IM drive. Lastly. section IV discusses the simulation result of the proposed MLI based THD reduction DTC IM drives obtained from Simulink.

\section{MATHEMATICAL MODEL OF INDUCTION MOTOR}

The dynamic behavior of an IM can be described from time-varying voltage equation and torque equation [1]. With the elimination of time-varying inductance, the complexity of the equation can be reduced. The time-varying inductance in voltage equation of IM that caused by electric circuit in relative motion can be eliminate by relocated the rotor and stator variables to reference frame, which remains stationary or rotating at angular velocity [19][20].

IM with synchronous rotating reference frame is used in this paper due to the variable including current, voltage or flux linkage is stationary and fixed in constant magnitude in the synchronous frame. The mathematical equations of an IM are quizzes by dq0 equivalent circuit of IM as shown in figure 2 [21]. Three-phase stator voltage equation of an IM under equilibrium situation derived as:

$$
\begin{gathered}
V_{a}=\sqrt{2} V_{r m s} \sin (\omega t) \\
V_{b}=\sqrt{2} V_{r m s} \sin (\omega t-2 \pi / 3) \\
V_{c}=\sqrt{2} V_{r m s} \sin (\omega t+2 \pi / 3)
\end{gathered}
$$

The flux linkage of the rotor and stator in stator reference frame can be derived as below:

$$
\begin{aligned}
& \lambda_{q s}=L_{l s} i_{q s}+L_{m} i_{q r} \\
& \lambda_{d s}=L_{l s} i_{d s}+L_{m} i_{d r} \\
& \lambda_{q r}=L_{l r} i_{q r}+L_{m} i_{q s} \\
& \lambda_{d r}=L_{l r}+L_{m} i_{d s}
\end{aligned}
$$

From equation (4), (5), (6) and (7), the voltage equation of rotor and stator at dq axis of an IM is given by:

$$
\begin{gathered}
V_{q r}=r_{r} i_{q r}-\omega_{r} \lambda_{d r}+d \lambda_{q r} / d t \\
V_{d r}=r_{r} i_{d r}+\omega_{r} \lambda_{q r}+d \lambda_{q r} / d t \\
V_{d s}=r_{s} i_{d s}+d \lambda_{q s} / d t \\
V_{q s}=r_{s} i_{q s}+d \lambda_{q s} / d t
\end{gathered}
$$

Therefore, the torque of IM can be expressed as:

$$
T_{e}=3 / 2(P / 2)\left(\lambda_{q r} i_{d r}-\lambda_{d r} i_{q r}\right)
$$

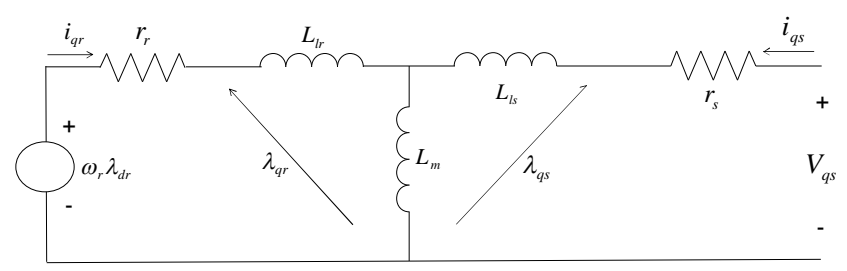

(a) Q-equivalent circuit

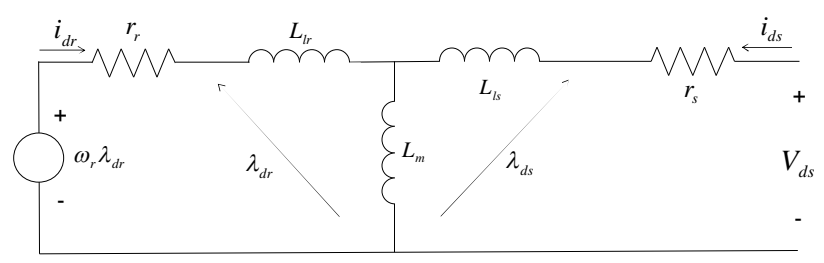

(b) D-equivalent circuit

Figure 2: Equivalent circuit diagram of IM in dq0 frame 
S. K. Chien et al., International Journal of Advanced Trends in Computer Science and Engineering, 9(1.4), 2020, $269-276$

\section{PROPOSED MLI BASED THD REDUCTION DTC IM DRIVES}

In this paper, MLI is applied in DTC IM drive to reduce THD of the drive system. The simplified block diagram of the proposed MLI based THD reduction DTC IM drive is shown in Figure 3. DTC of IM with space vector pulse width modulation (SVPWM) technique is proposed to implement in this study due to the advantages of the SVPWM in low current distortion and low torque ripple compared to hysteresis controller [22][23]. For the conventional DTC IM, the working principle of the system is to use the flux error and torque error that generated from the difference between the reference flux and reference torque with estimated flux and estimated torque respectively. In the proposed SVPWM control technique, it used eight sorts of different switch modes (two zero voltage vector and six non-zero voltage vector) of VSI to attains high control performance and control the stator flux to approach the reference flux circle. Simulink model of DTC IM drive with the conventional two-level inverter and Simulink model of the proposed MLI based THD reduction DTC IM drive are shown in Figure 4 and Figure 5 respectively. The specification of IM used in both Simulink model is shown in Table 1.

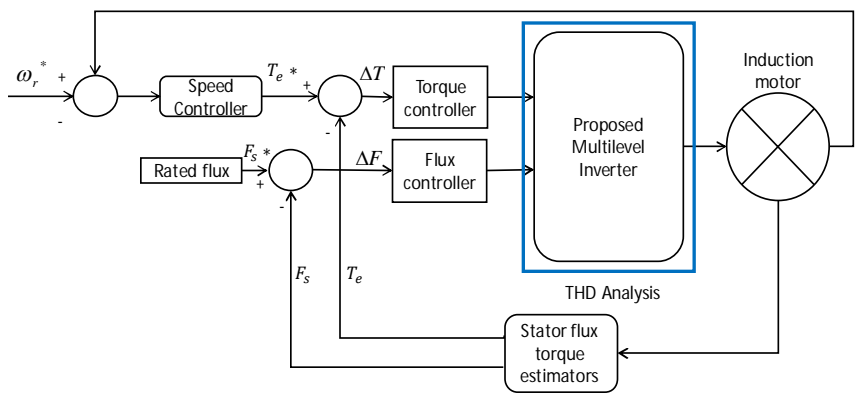

Figure 3: Block diagram of proposed MLI based THD reduction DTC IM drive

THD is a method used to compute harmonic order present in current or voltage waveform. Furthermore, output current or voltage quality and sinusoidal wave quality also can analyse by using THD [24]. THD is prescribe as the ratio of root mean square (rms) value of harmonic component to the rms value of the fundamental component [13][25].

$$
\begin{gathered}
T H D_{I} \%=\sqrt{\sum_{n=2}^{\infty}\left(I_{o h, r m s}\right)^{2}} / I_{o r, r m s} \\
T H D=I_{h} / I_{s r}
\end{gathered}
$$

Equation (14) represents the current THD, where,

$I_{h}$ is the rms value of harmonic component of rotor current,

$I_{s r}$ is the rms value of fundamental component of current supply.

The importance of reducing harmonic distortion is for appropriate execution of system [13][26]. Fourier analysis is the basic operation of frequency-domain method. Frequency-domain method offers quick outcome at minimum calculation therefore real-time implementation in digital signal processing (DSP) can be done. Harmonic distortion detection can classify into three types, namely fast fourier transform (FFT), discrete fourier transform (DFT), and recursive discrete fourier transform (RDFT) [13][27]. FFT technique of frequency domain is used in this study for computation of fundamental components of voltage and current.

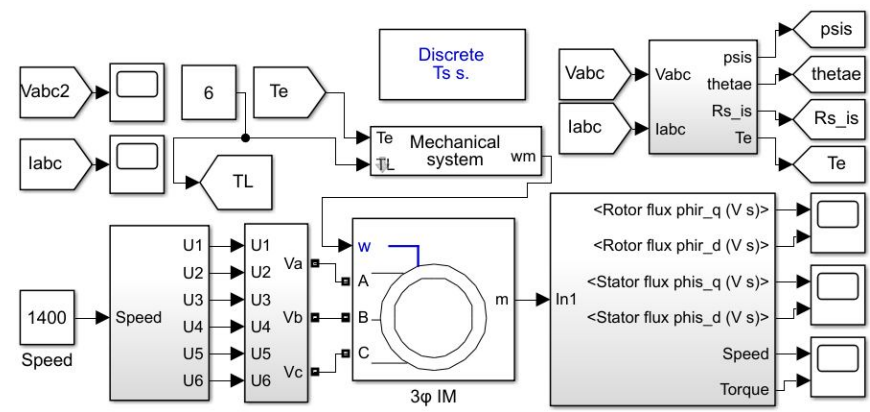

Figure 4: Conventional DTC IM drive with conventional inverter

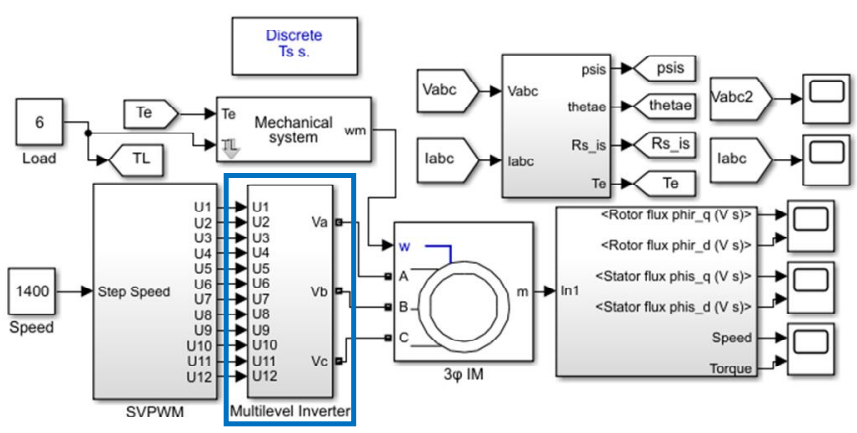

Figure 5: Proposed MLI based THD reduction DTC IM drive

\begin{tabular}{|c|c|}
\hline $\begin{array}{c}\text { Specification of } \\
\text { IM }\end{array}$ & Parameters \\
\hline Mechanic power & $5.4 \mathrm{HP}, 4 \mathrm{KW}$ \\
\hline Rated voltage & $400 \mathrm{~V}$ \\
\hline Rated frequency & $50 \mathrm{~Hz}$ \\
\hline Rotor speed & $1430 \mathrm{rpm}$ \\
\hline Number of poles & 4 \\
\hline \multicolumn{2}{|c|}{ IM parameters and type of frame } \\
\hline Reference frame & Stationary \\
\hline Stator resistance & $1.405 \Omega$ \\
\hline Rotor resistance & $1.395 \Omega$ \\
\hline Stator inductance & $5839 \mathrm{mH}$ \\
\hline Rotor inductance & $5839 \mathrm{mH}$ \\
\hline
\end{tabular}

Table 1: IM specification

\section{RESULT AND DISCUSSION}

To verify the effectiveness of the proposed MLI based THD reduction DTC IM drive, the corresponding result of THD, speed response, and load torque response for the proposed MLI based THD reduction DTC IM drive is observed at low 
S. K. Chien et al., International Journal of Advanced Trends in Computer Science and Engineering, 9(1.4), 2020, 269- 276

speed $(300 \mathrm{rpm})$, medium speed $(850 \mathrm{rpm})$ and high rotating speed $(1400 \mathrm{rpm})$ with constant load torque of $6 \mathrm{Nm}$. In each different speed testing, the resulting THD of proposed MLI based THD reduction DTC IM drive obtained is compared with the conventional DTC IM drive. Figure 6 shows the speed and load torque of proposed MLI based THD reduction DTC IM drive, and figure 7, 8 and 9 show the FFT result of current, $I_{a}, I_{b}$, and $I_{c}$ respectively when the speed of IM is 300 rpm.
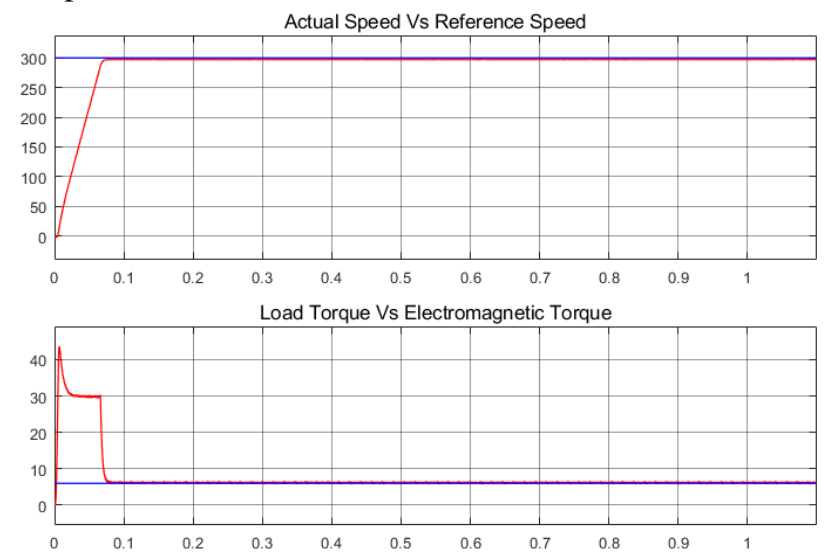

Figure 6: Speed and load torque response of proposed MLI based THD reduction DTC IM drive for low speed (300rpm)

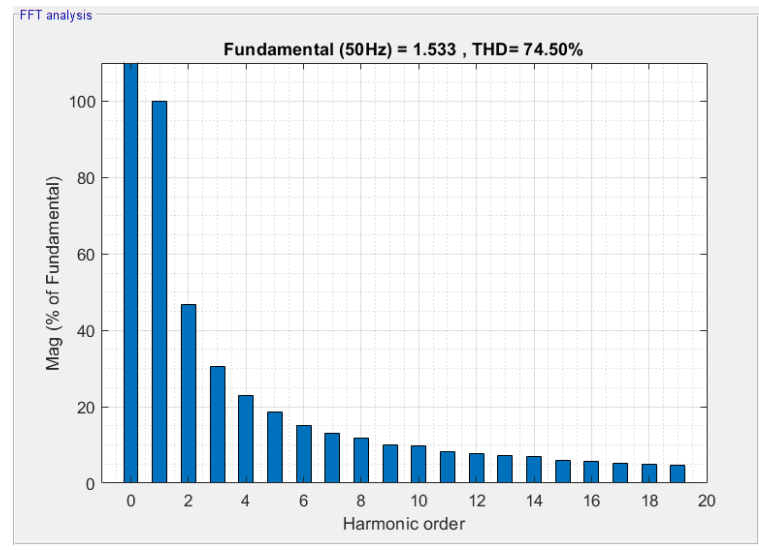

(a)

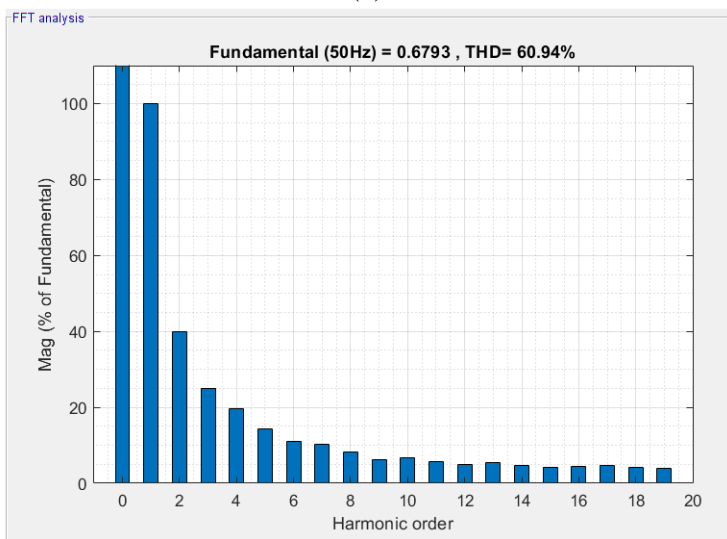

(b)

Figure 7: FFT result of current, $I_{a}$ when low speed (300rpm). (a) Conventional inverter (b) Proposed MLI based THD reduction DTC IM drive

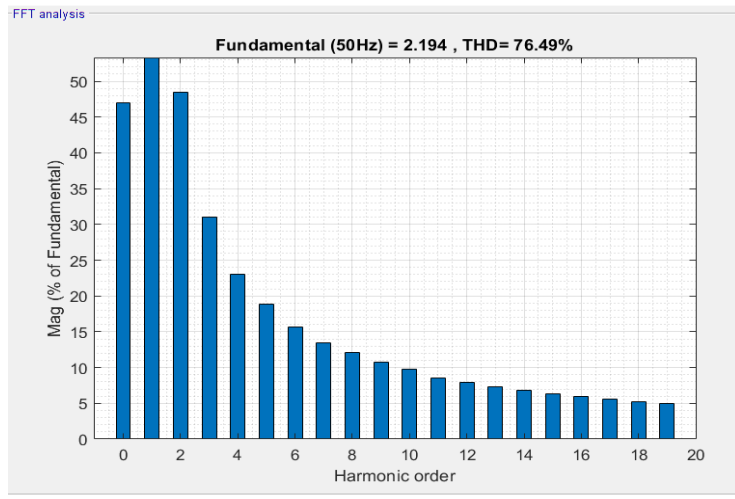

(a)

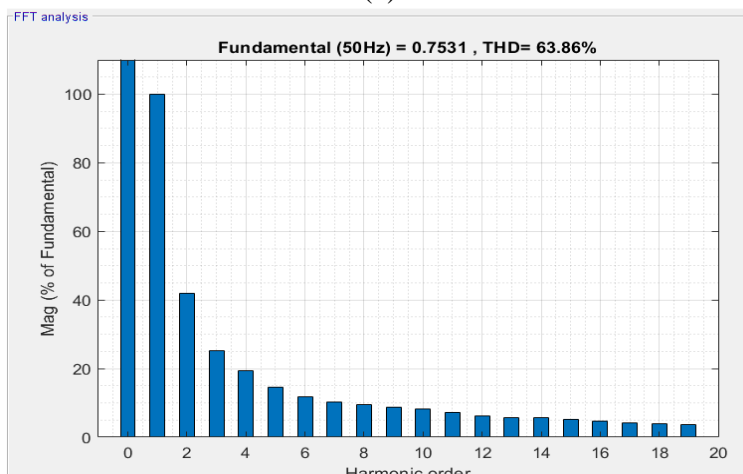

(b)

Figure 8: FFT result of current, $I_{b}$ when low speed (300rpm). (a) Conventional inverter (b) Proposed MLI based THD reduction DTC IM drive

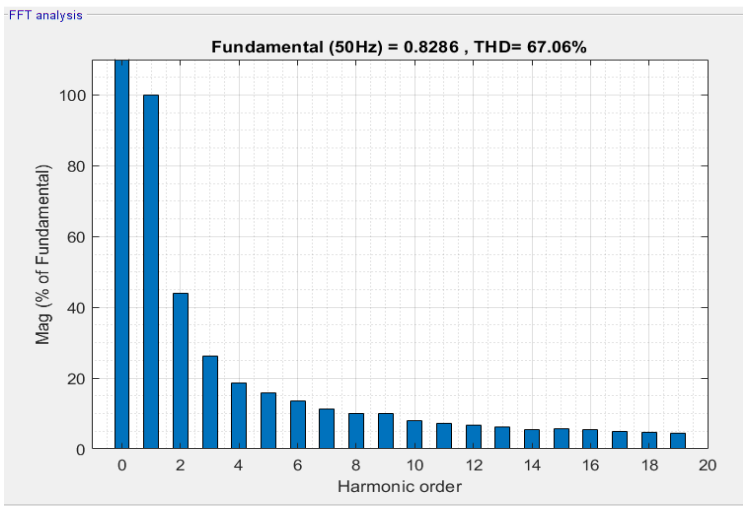

(a)

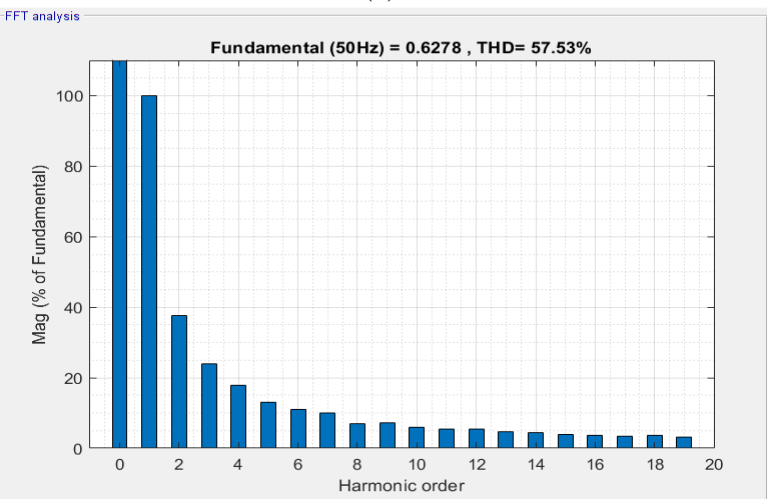

(b)

Figure 9: FFT result of current, $I_{c}$ when low speed (300rpm). (a) Conventional inverter (b) Proposed MLI based THD reduction DTC IM drive 
S. K. Chien et al., International Journal of Advanced Trends in Computer Science and Engineering, 9(1.4), 2020, $269-276$

Figure 10 shows the speed and load torque of proposed MLI based THD reduction DTC IM drive, while figure 11, 12 and 13 shows the FFT result of current, $I_{a}, I_{b}$, and $I_{c}$ respectively when speed of IM is $850 \mathrm{rpm}$.

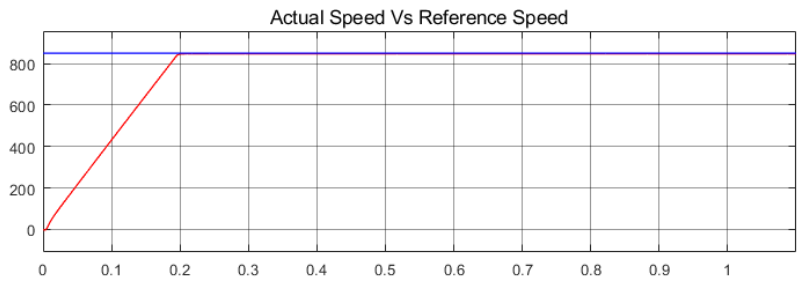

Load Torque Vs Electromagnetic Torque

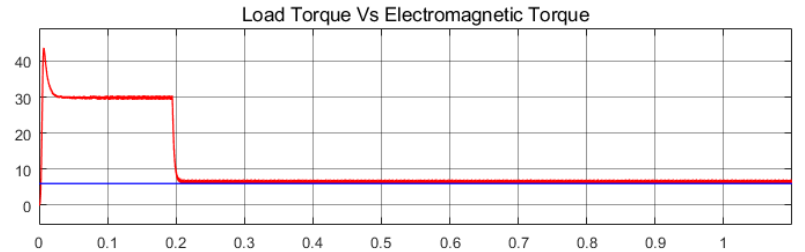

Figure 10: Speed and load torque of proposed MLI based THD reduction DTC IM drive for medium speed (850rpm)



(a)

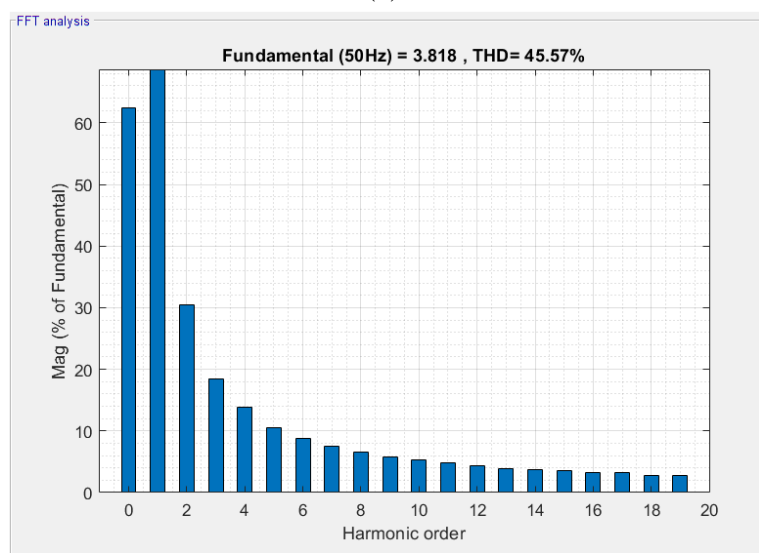

(b)

Figure 11: FFT result of current, $I_{a}$ when medium speed (850rpm).

(a) Conventional inverter (b) Proposed MLI based THD reduction DTC IM drive

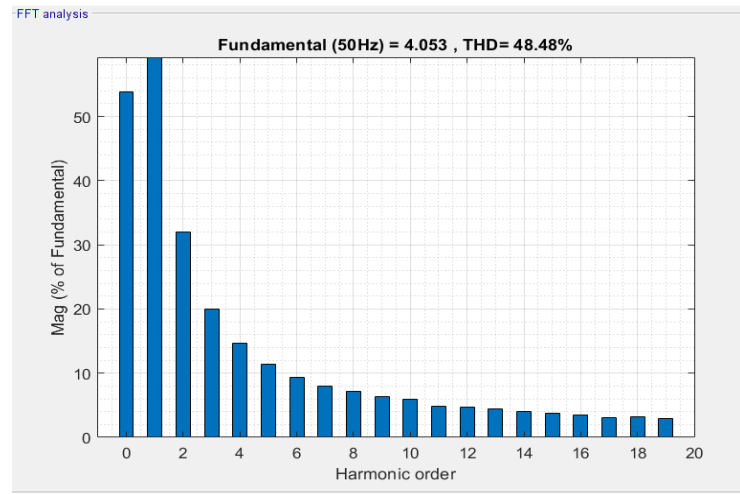

(a)

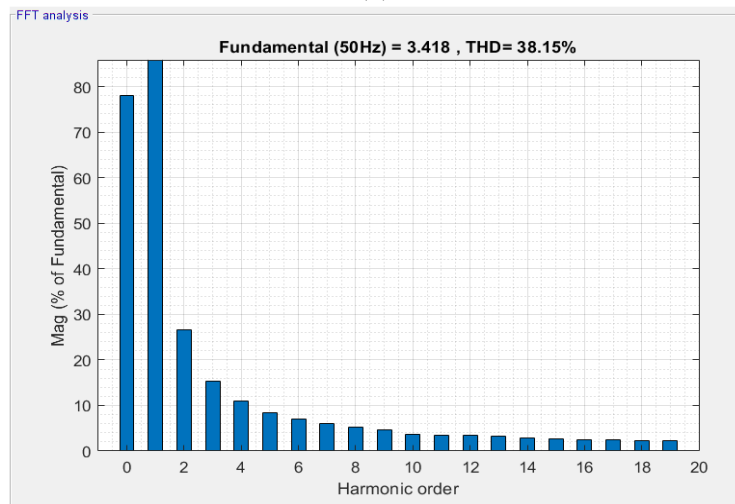

(b)

Figure 12: FFT result of current, $I_{b}$ when medium speed (850rpm).

(a) Conventional inverter (b) Proposed MLI based THD reduction DTC IM drive

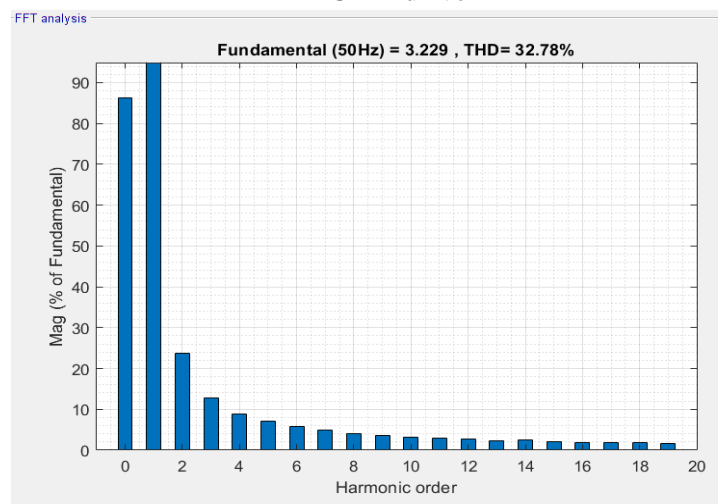

(a)

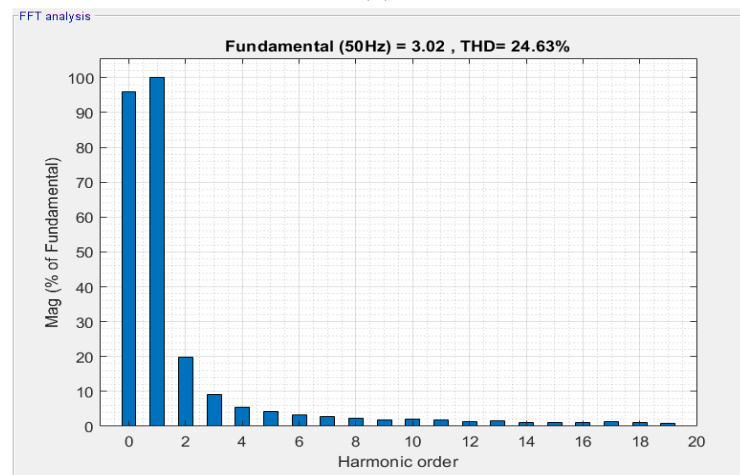

(b)

Figure 13: FFT result of current, $I_{c}$ when medium speed (850rpm).

(a) Conventional inverter (b) Proposed MLI based THD reduction DTC IM drive 
S. K. Chien et al., International Journal of Advanced Trends in Computer Science and Engineering, 9(1.4), 2020, $269-276$

And lastly, figure 14 shows the speed and load torque of proposed MLI based THD reduction DTC IM drive, and figure 15, 16 and 17 shows the FFT result of current, $I_{a}, I_{b}$, and $I_{c}$ respectively when speed of IM is 1400rpm.
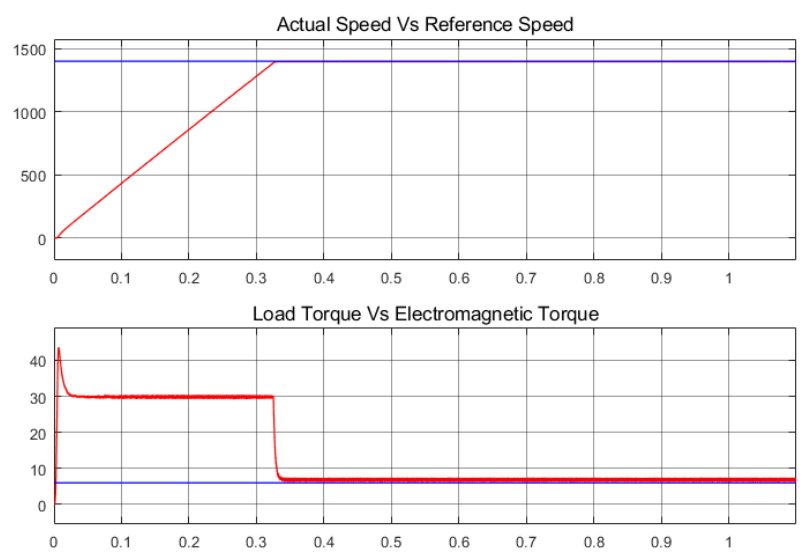

Figure 14: Speed and load torque of proposed MLI based THD reduction DTC IM drive for high speed (1400rpm)

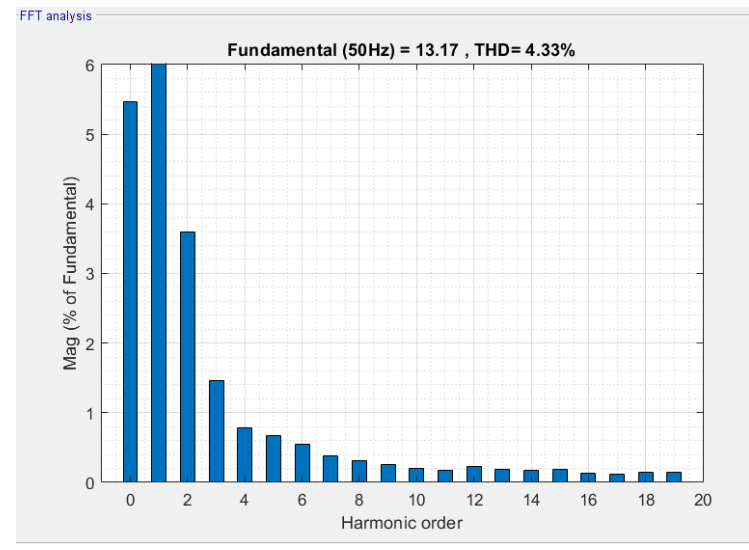

(a)



(b)

Figure 15: FFT result of current, $I_{a}$ when high speed (1400rpm). (a) Conventional inverter (b) Proposed MLI based THD reduction DTC IM drive

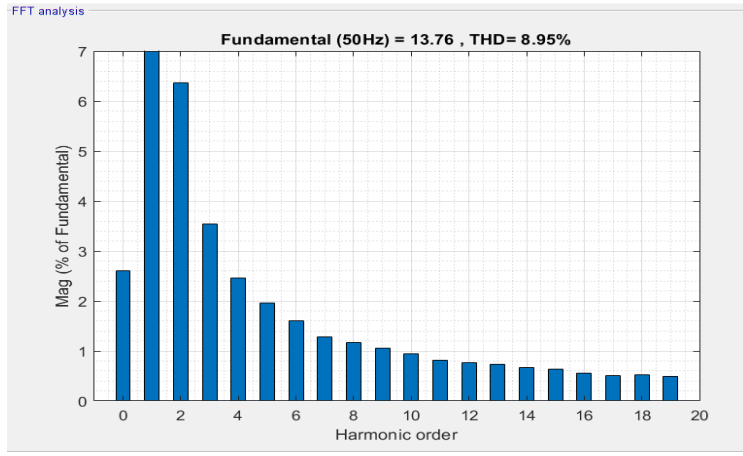

(a)

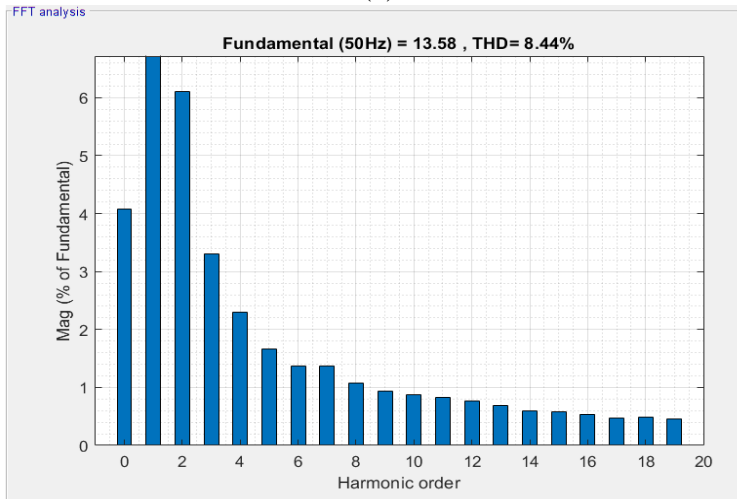

(b)

Figure 16: FFT result of current, $I_{b}$ when high speed (1400rpm).

(a) Conventional inverter (b) Proposed MLI based THD reduction DTC IM drive

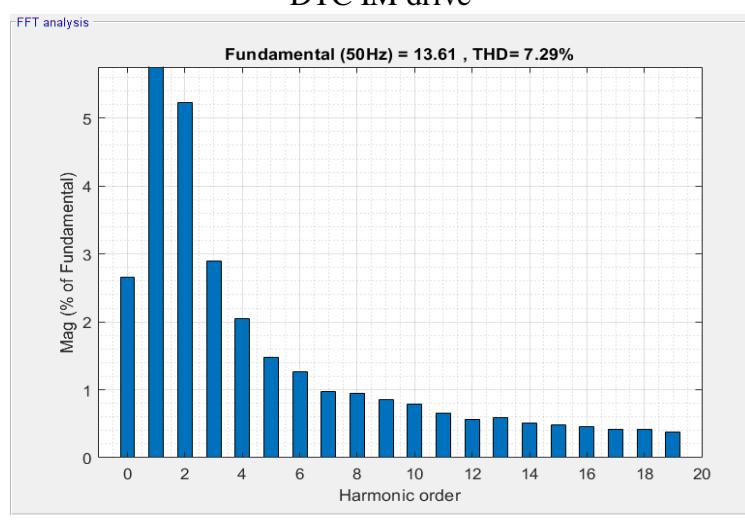

(a)

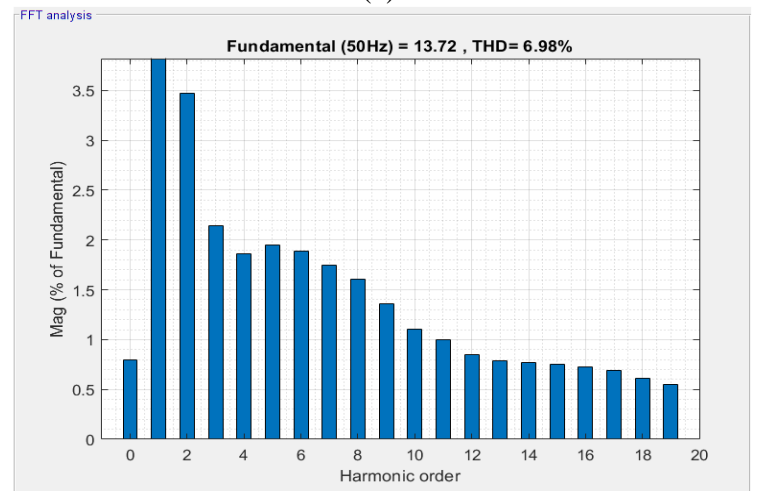

(b)

Figure 17: FFT result of current, $I_{c}$ when high speed (1400rpm).

(a) Conventional inverter (b) Proposed MLI based THD reduction DTC IM drive 
S. K. Chien et al., International Journal of Advanced Trends in Computer Science and Engineering, 9(1.4), 2020, 269- 276

The THD for proposed MLI based THD reduction DTC IM drive and DTC IM drive with a conventional inverter at low speed, medium speed and high rotating speed of IM with constant load torque $6 \mathrm{Nm}$ are summarised in table 2 . It is observed that THD of the IM drive is considerably reduced with the proposed MLI based THD reduction DTC IM drive as compared with DTC IM drive with the conventional inverter. Besides that, when simulation are conducted with low speed to high rotating speed of IM, it also can be observed that THD of the IM drive reduced from low speed to high speed condition and when IM operates at rated condition (1400 rpm), the THD of IM drive is minimum. In addition, the speed and torque performances of IM is not affected with the proposed MLI based THD reduction DTC IM drive as shown in figure 6, figure 10 and figure 14 for low speed, medium speed and high rotating speed of IM respectively.

Table 2: THD of DTC IM drives with and without MLI corresponding to different speed

\begin{tabular}{|c|c|c|c|c|c|c|}
\hline \multicolumn{9}{|c|}{ THD (\%) } \\
\hline Current & \multicolumn{2}{|c|}{$I_{a}$} & \multicolumn{2}{c|}{$I_{b}$} & \multicolumn{2}{c|}{$I_{c}$} \\
\hline $\begin{array}{c}\text { Speed } \\
\text { (rpm) }\end{array}$ & $\begin{array}{c}\text { Convent- } \\
\text { ional }\end{array}$ & $\begin{array}{c}\text { Proposed } \\
\text { MLI }\end{array}$ & $\begin{array}{c}\text { Convent- } \\
\text { ional }\end{array}$ & $\begin{array}{c}\text { Proposed } \\
\text { MLI }\end{array}$ & $\begin{array}{c}\text { Convent- } \\
\text { ional }\end{array}$ & $\begin{array}{c}\text { Proposed } \\
\text { MLI }\end{array}$ \\
\hline 300 & 74.50 & 60.94 & 76.49 & 63.86 & 67.06 & 57.53 \\
\hline 850 & 55.45 & 45.57 & 48.48 & 38.15 & 32.78 & 24.63 \\
\hline 1400 & 4.33 & 4.03 & 8.95 & 8.44 & 7.29 & 6.98 \\
\hline
\end{tabular}

\section{CONCLUSION}

In conclusion, proposed three-level MLI are realized in MATLAB Simulink with PWM as the control strategy that control the switching of MLI in IM drive. With the proposed MLI based THD reduction DTC IM drive is applied in this study, the simulation result shows that the appropriate operation of the MLI results in reducing the THD of the motor drive system. The simulation result of conventional inverter based DTC IM drive shows the robustness and simplicity of the drive system, but there are high switching loss and torque ripples while for the proposed MLI based THD reduction DTC IM drive will reduce the switching losses and torque ripples, but increase the drive system complexity. From this study, with the proposed MLI based THD reduction DTC IM drive, THD of the DTC IM drive can be reduced approximately at an average $11.91 \%$ for low speed operation, $9.45 \%$ for medium speed operation and $0.37 \%$ for high speed operation.

\section{ACKNOWLEDGEMENT}

The authors would like to thank the Ministry of Education, Malaysia (MOE) and the Research Management Centre (RMC), Universiti Tun Hussein Onn Malaysia (UTHM) for financially supporting this research under the Fundamental Research Grant Scheme (FRGS) Vot.No. FRGS/1/2018/TK10/UTHM/03/8 and partially sponsored by Universiti Tun Hussein Onn Malaysia.

\section{REFERENCES}

[1] M. Sreejeth, M. Singh, and P. Kumar, "Efficiency optimization of vector controlled induction motor drive," IECON Proc. Industrial Electron. Conf., pp. 1758-1763,2012,doi:10.1109/IECON.2012.6388935

[2] P. J. Koratkar and A. Sabnis, "Comparative analysis of different control approaches of direct torque control induction motor drive," 2017 Int. Conf. Intell. Comput. Instrum. Control Technol. ICICICT 2017, vol. 2018-Janua, no. 3, pp. 831-835, 2018, doi: 10.1109/ICICICT1.2017.8342672.

[3] S. Y. Sim, W. M. Utomo, Z. A. Haron, A. A. Bohari, N. M. Zin, and R. M. Ariff, "Neural network SVPWM-DTC of induction motor for EV load model," Proc. - 2014 Electr. Power, Electron. Commun. Control Informatics Semin. EECCIS 2014. conjunction with 1st Jt. Conf. UB-UTHM, vol. 00, no. c,pp.23-28,2014,doi:10.1109/EECCIS.2014.7003713.

[4] N. Pimkumwong and M. S. Wang, "Direct torque control of three-phase induction motor based on constant voltage per frequency control with simple controller," 1st Int. ECTI North. Sect. Conf. Electr. Electron. Comput. Telecommun. Eng. ECTI-NCON 2018, no. 1, pp. 15-20, 2018, doi: 10.1109/ECTI-NCON.2018.8378273.

[5] R. Kumar Bindal and I. Kaur, "Comparative analysis of different controlling techniques using direct torque control on induction motor," Proc. 2016 2nd Int. Conf. Next Gener. Comput. Technol. NGCT 2016, no. October, pp. 191-196, 2017, doi: 10.1109/NGCT.2016.7877413.

[6] M. R. Pawar and P. A. Jhala, "Direct Torque Control of Induction Motor Drives," Ijireeice, vol. 4, no. 1, pp.108-111,2016, doi: 10.17148/ijireeice.2016.4126.

[7] S. H., K. S.F., and S. B., "Improvements in direct torque control of induction motor for wide range of speed operation using fuzzy logic," J. Electr. Syst. Inf. Technol., vol. 5, no. 3, pp. 813-828, 2017, doi: 10.1016/j.jesit.2016.12.015.

[8] W. M. Utomo, S. Y. Sim, Z. A. Haron, A. A. Bohari, N. M. Zin, R. M. Ariff and W. A. Siswanto "An improved DTC of an induction motor drive with neural network controller," Int. J. Mech. Mechatronics Eng., vol. 14, no. 2, pp. 54-59, 2014.

[9] W. M. Utomo, S. Y. Sim, Z. A. Haron, A. A. Bohari, and N. M. Zin, "Online adaptive flux control for space vector PWM-DTC IM drives towards optimum efficiency design," ARPN J. Eng. Appl. Sci., vol. 10, no. 19, pp. 9099-9105, 2015.

[10] B. P. Ganthia, S. R. Sahu, S. Biswal, A. Abhisekh, and S. K. Barik, "Genetic algorithm based direct torque control of vsi fed induction motor drive using matlab simulation," Int. J. Adv. Trends Comput. Sci. Eng., vol. 8, no. 5, pp. 2359-2369, 2019, doi: 10.30534/ijatcse/2019/76852019. 
S. K. Chien et al., International Journal of Advanced Trends in Computer Science and Engineering, 9(1.4), 2020, $269-276$

[11] F. Sedaghati and S. H. Latifi, "Application of a three-phase multilevel inverter for DTC based induction motor drive," 9th Annu. Int. Power Electron. Drive Syst. Technol. Conf. PEDSTC 2018, vol. 2018-Janua, no. Mv, pp. 443-448, 2018, doi: 10.1109/PEDSTC.2018.8343838.

[12] W. M. Utomo, S. Y. Sim, Z. A. Haron, A. A. Bohari, and N. M. Zin, "Modeling of A Single Phase 7-Level Cascaded H-Bridge Multilevel Inverter," Int. J. Eng. Technol., vol. 7, no. 2, pp. 327-330, 2018.

[13] N. Thakur and R. S. Lodhi, "THD Analysis of Output Voltage for VSI fed Induction Motor Drives," Int. J. of Eng. and Management Research, no. 4, pp. 130-133, 2014.

[14] S. Y. Sim et al., "Enhance cascaded H-bridge multilevel inverter with artificial intelligence control," Indones. J. Electr. Eng. Comput. Sci., vol. 11, no. 1, pp. 105-112, 2018, doi: 10.11591/ijeecs.v11.i1.pp105-112.

[15] K. U. Leuven, F. Ingenieurswetenschappen, and O. Electa, "Review of various method in improvement in speed, power and efficiency of induction motor," Int. Conf. on Energy, Comm., Data Analytic and Soft Computing, no. December, pp. 3293-3296, 2008.

[16] A. Chitra and S. Himavathi, "Investigation and analysis of high performance green energy induction motor drive with intelligent estimator," Renew. Energy, vol. 87, pp. 965-976, 2016, doi: 10.1016/j.renene.2015.07.084.

[17] A. Ansari, S. Jain, S. P. Phulambikar, and S. Gupta, "Performance and Analysis with Power Quality Improvement with Induction Motor in Electric Drive," Int. J. of Eng. and Tech. Research, no. 10, pp. 30-34, 2014.

[18] K. Rajani and D. V. N. Ananth, "Simulation Analysis of Three, Five, Thirteen, Fifteen , Twenty One and Thirty One Level Cascaded H-Bridge Multilevel Inverter," Int. J. for Research in Appl. Sci. and Eng. Tech., vol. 5, no. Viii, pp. 2283-2292, 2017.

[19] H. Hashimoto, Y. Ohno, S. Kondo, and F. Harashima, "Torque control of induction motor using predictive observer," vol. 180, no. May, pp. 271-278, 2003, doi: 10.1109/pesc.1989.48499.

[20] R. Dharmaprakash and J. Henry, "Direct Torque Control of Induction Motor Using Multilevel Inverter," Inter. J. of Latest Research in Sci. and Tech., vol. 3, no. 3, pp. 70-75, 2014.

[21] T. Rai and P. Debre, "Generalized modeling model of three phase induction motor," 2016 Int. Conf. Energy Effic. Technol. Sustain. ICEETS 2016, pp. 927-931,2016, doi: 10.1109/ICEETS.2016.7583881.

[22] G. Durgasukumar and M. K. Pathak, "THD reduction in performance of multi-level inverter fed induction motor drive," India Int. Conf. Power Electron. IICPE 2010, pp. 1-6, 2011, doi:
10.1109/IICPE.2011.5728116.

[23] P. Farhadi, M. Gheydi, F. Abdolahnejad, and A. Johari Pireivatloo, "Simultaneous improvement of distortion of current and torque in induction motor by optimization of linkage flux distortion," 8th Power Electron. Drive Syst. Technol. Conf. PEDSTC 2017, no. Pedstc, pp. 73-77, 2017, doi: 10.1109/PEDSTC.2017.7910393.

[24] M. D. Kumar, S. F. Kodad, and B. Sarvesh, "Simplified Fault Detection Algorithm for Voltage Source Fed Induction Motor," Mater. Today Proc., vol. 5, no. 1, pp. 1401-1410, 2018, doi: 10.1016/j.matpr.2017.11.226.

[25] P. V. Kapoor and M. M. Renge, "Improved Performance of Modular Multilevel Converter for Induction Motor Drive," Energy Procedia, vol. 117, pp.361-368,2017,doi:10.1016/j.egypro.2017.05.146.

[26] M. Rusli, M. A. Choiron, and M. A. Muslim, "Modified loop shaping algorithm in designing 2-DOF controller of a ladder-secondary double-sided linear induction motors," Int. J. Adv. Trends Comput. Sci. Eng., vol. 8, no. 1.6 Special Issue,pp.536-542,2019,doi:10.30534/ijatcse/2019/79 81.62019 .

[27] L. Asiminoaei, F. Blaabjerg, and S. Hansen, "Evaluation of harmonic detection methods for active power filter applications," Conf. Proc. IEEE Appl. Power Electron. Conf. Expo. - APEC, vol. 1, pp.635-641,2005,doi:10.1109/APEC.2005.1453014. 